\title{
DETERMINATION OF THE BIOADHESION INDICATORS OF VAGINAL GEL WITH RESVERATROL AND HYALURONIC ACID
}

\author{
Olena Ivaniuk \\ Department of Technology of Drugs \\ National University of Pharmacy \\ 53 Pushkinska str., Kharkiv, Ukraine, 61002 \\ Tatyana Yarnykh \\ Department of Technology of Drugs \\ National University of Pharmacy \\ 53 Pushkinska str., Kharkiv, Ukraine, 61002 \\ Inna Kovalevska \\ Department of Industrial Technology of Drugs \\ National University of Pharmacy \\ 53 Pushkinska str., Kharkiv, Ukraine, 61002
}

\begin{abstract}
Aim. The purpose of the work is to determine the bioadhesion indices of vaginal gel with resveratrol and hyaluronic acid, as well as the choice of the type and content of mucoadhesives in the composition.

Materials and methods. As research objects samples of gels with different mucoadhesives in the composition were used. Among used mucoadhesives were: sodium alginate (FMC BioPolimer AS, Norway), methyl cellulose (Shin Etsu, Germany), Methocel - methyl cellulose with hydroxypropylmethyl cellulose (Dow Pharmaceutical Sciences, USA), OraRez ${ }^{\circledR}$ W-100L16 - vinyl methyl ether and maleic anhydride copolymer (BOAI, China). As a comparison drug, vaginal gel "Gynodec" (Yuriya-Pharm) was used. During the study, the rate of gel distribution, the degree of deformation under the influence of mechanical forces, the degree of the gel fixation on the surface of the mucosa and the adhesion ability of the samples have been determined.

Results. The study has determined that sample No. 2 with sodium alginate has the highest distribution rate, which was $1.56 \mathrm{~cm} / \mathrm{min}$. The study of the fixation of samples on the surface of the model of the mucous was performed by the method of flow. The results have showed that the sample with sodium alginate has the closest value to the reference drug. The adhesive ability of samples with different sodium alginate contents was determined. The tensimetric study has found that at a concentration of $0.5 \%$, the force required to separate the surface is $6158 \mathrm{~Pa}$.

Conclusions. On the basis of the complex of physico-chemical studies, bioadhesion indicators of vaginal gel with resveratrol, depending on the type and concentration of mucoadhesives have been determined. According to the distribution parameters on the surface of the genital mucosa model, it has been found that the best properties compared with other types of mucoadhesives has a sample containing sodium alginate. The study by means of a strain gauge has found that the addition of sodium alginate at a concentration of $0.5 \%$ would provide a satisfactory adhesive ability of the vaginal gel.

Keywords: vaginal gel, bioadhesion, mucoadhesives, sodium alginate, resveratrol, hyaluronic acid, membrane, hormonal disorders, climacteric, prolonged action.
\end{abstract}

\section{Introduction}

Among vaginal dosage forms, gels are widespread, due to the ability to provide prolonged moisturizing action, ease of use and dosage [1].

When developing the composition and technology of vaginal gels in addition to rheological characteristics it is important to evaluate the degree of bioadhesion, which determines the possibility of keeping an active pharmaceutical ingredient (API) on the surface of the affected organ by means of interphase forces for a long time [2]. If adhesive fixation occurs to the mucous membrane, this process is called mucoadhesion, which determines the time of drug retention on the surface, 
its uniform distribution, the absence of premature evacuation of the administered dose and the completeness of the API release [3, 4].

Properties of the mucous tissue of genital organs are due to the presence of specific glycoproteins - mucins, which are located on the apical surface of the epithelial layer or as a part of the mucus. Interaction with mucins and the possibility of long-term fixation with controlled release of active substances are provided by mucoadhesive substances, as which most often use hydrophilic polymers. They have numerous hydrophilic groups that promote adhesion and cause the swelling of polymers in the fluid and thus increase the amount of adhesive sites $[5,6]$.

\section{Aim of research}

The aim of the work is to determine the bioadhesion indices of vaginal gel with resveratrol and hyaluronic acid, as well as the choice of the type and content of mucoadhesives in the composition.

\section{Objects and methods.}

The subject of the study were samples of vaginal gels with different mucoadhesives at a concentration of $0.5 \%$ [1]. The composition of the prototype samples is given in Table $\mathbf{1}$.

Table 1

Composition of prototype samples

\begin{tabular}{cccccc}
\hline \multirow{2}{*}{ The name of the substance } & \multicolumn{3}{c}{ Sample number } \\
\cline { 2 - 6 } & $\mathbf{1}$ & $\mathbf{2}$ & $\mathbf{3}$ & $\mathbf{4}$ & $\mathbf{5}$ \\
\hline Hyaluronic acid & + & + & + & + & + \\
Resveratrol & + & + & + & + & + \\
Propylene glycol & + & + & - & - & + \\
Aristoflex & + & + & + & - & - \\
Sodium alginate & - & + & - & + \\
Methylcellulose & - & - & - & -
\end{tabular}

Among used mucoadhesives were: sodium alginate (FMC BioPolimer AS, Norway), methylcellulose (Shin Etsu, Germany), Methocel - methylcellulose with hydroxypropyl methylcellulose (Dow Pharmaceutical Sciences, USA), OraRez ${ }^{\circledR} \mathrm{W}-100 \mathrm{~L} 16$ - copolymer of vinyl methyl ether and maleic anhydride (BOAI, China).

As a reference drug, the vaginal gel "Gynodek" (Yuriya-Pharm), which contains hyaluronic acid $-2.5 \%$ (sample number 6), was used.

Vaginal dosage forms have a short residence time at the place where the drug is applied, therefore, for its control as well as determination of fixation degree the rates of distribution and adhesion have been determined [7, 8].

The study of the gel distribution rate was carried out using a polymeric film of borosilicate fibre (manufactured in Japan) with a layer of $3.7 \%$ solution of hydroxypropylmethylcellulose, which simulated vaginal mucus. The film was mounted at an angle of $25^{\circ}$, which corresponds to the physiological location of the vagina relative to the vertical axis of the vertebral column. On the film surface, the starting line was marked and applied $1.0 \mathrm{~g}$ of a sample. The time of the experiment was 10 minutes, which corresponds to the physiological rate of vaginal secretion. After that, measured the distance from the point of the gel application to the end point of the path and calculated the average speed of its distribution $[9,10]$. 
Study of the deformation degree during loading was carried out according to the following procedure: a film of borosilicate fibre was mounted on the surface of the object glass; The sample of the preparation in the amount of $0.5 \mathrm{~g}$ was applied to the film, covered with another sample glass and measured the diameter of the resulting spot. A load (100 g) was placed on the upper slide glass and measured the diameter of the spot after 5 minutes of the experiment. The distribution coefficient was calculated according to formula 1 [11].

$$
\mathrm{k}=\frac{\mathrm{d}_{\max }}{\mathrm{d}_{0}},
$$

where $d_{0}-$ the initial diameter of the gel spot; $d_{\max }-$ The diameter of the spot after 5 minutes of the experiment.

Determination of the degree of gel samples dilution by cervical mucus was carried out by the method of "flow" [10]. On the model membrane, the test gel samples were applied in an amount of $0.5 \mathrm{~g}$ and placed in a Petri dish with $25 \mathrm{ml}$ of physiological saline of $\mathrm{pH} 4.0$ for 1 hour. Carried out the organoleptic analysis and calculation of samples' spot areas by the formula (2).

$$
\mathrm{S}=\mathrm{d}^{2} \times \frac{\pi}{4}
$$

where $d^{2}$ - diameter of the gel sample spot.

The study of adhesion ability was carried out using a tensiometer, recording of the indicators was carried out using an electronic dynamometer. The test specimen was placed in a petri dish fixed on a horizontal surface. The weight of the test sample was calculated from the ratio of $0.25 \mathrm{~g} / \mathrm{cm}^{2}$ of the area of the cover plate, which provides the optimum thickness of the layer to measure the separation effort of the sample-plate contact surface. A sample of gel was pressed with a plate equipped with a rod to transfer the separation effort to the dynamometer, the contact surface was previously covered with a thin layer of paraffin until it was completely wetted with a sample. To provide a uniform effort, a load (6) weighing $1 \mathrm{~kg}$ was placed on the plate for 60 seconds, after which the load was removed. The dynamometer with the attached contact plate was lifted upright up to the detachment of the contact plate from the surface of the sample and fixed the required separation effort according to the dynamometer readings [12].

The calculation of adhesion was carried out with the force necessary for the separation of the two surfaces after the occurrence of adhesion [13]. The force was calculated by formula (2).

$$
\mathrm{Sm}=\frac{\mathrm{Fm}}{\mathrm{Ao}}
$$

where Fm - maximum separation force; Ao - total surface area.

\section{Research results}

At the first stage of the study, distribution rate of the vaginal gel specimens with different gel formers was measured (Fig. 1).

Ability to distribute under the action of external forces is an important characteristic of semisolid dosage forms, so at the next stage, the determination of the effect of mechanical force on the distribution of experimental samples on the surface of the model mucosa has been carried out (Fig. 2) [14, 15].

The next step was to determine the indices of samples fixation of on the surface of the application by the "flow" method $[16,17]$. The organoleptic parameters of the samples and the values of the spots area after application to the surface of the film are presented in Table 2. 


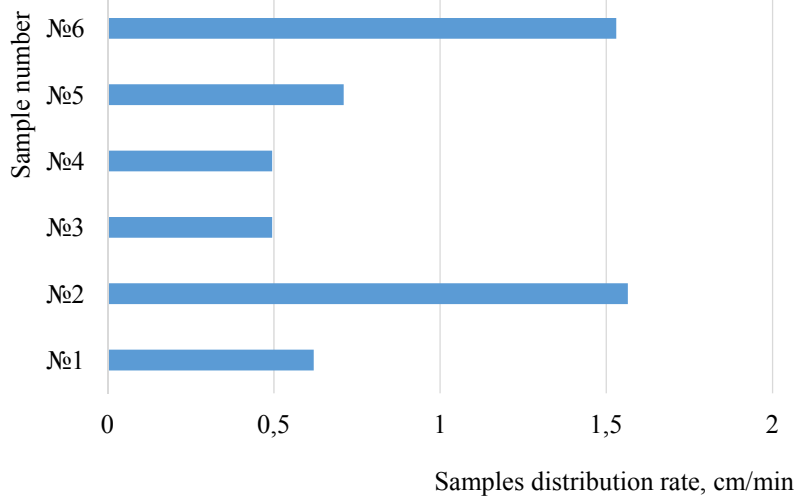

Fig. 1. Indicators of samples distribution rates

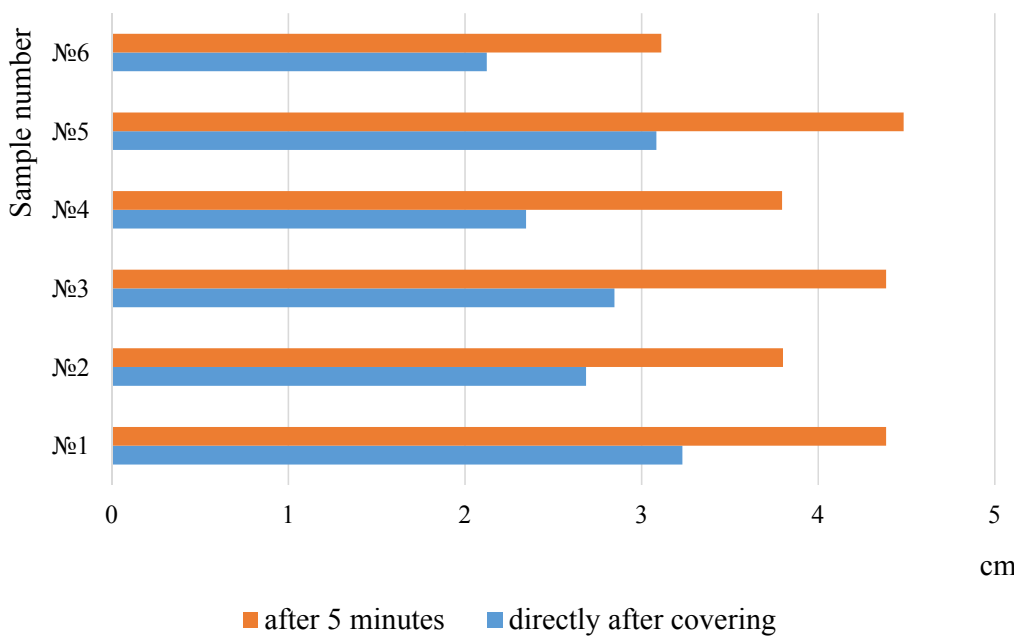

Fig. 2. Comparative characteristic of the diameter of the spots under the action of mechanical forces

\section{Table 2}

Comparative analysis of gel samples after blurring

\begin{tabular}{lllll}
\hline No. & d1 & d2 & $S$ & Description
\end{tabular}

$1 \quad 1 \quad 0.95 \pm 0.02$ There is a blur of the edges of the gel spot, the shape and relief do not change. Poor fixation on the film surface.

$2 \quad 1.6 \quad 1.92 .83 \pm 0.11 \quad$ Uniform blurring of the spot edges. Full fixation on the film.

$3 \quad 1.2 \quad 1.5 \quad 1.77 \pm 0.04 \quad$ Changing the shape of the spot, the shape of the gel spot has changed. Partial fixation on the film.

$4 \quad 1.2 \quad 1.5 \quad 1.77 \pm 0.05 \quad$ Uniform blurring of edges without changing shape and relief, partial fixation on the film.

$5 \quad 1.3 \quad 2.2 \quad 3.80 \pm 0.19$ Uniform blurring of the edges of the spot, no fixing on the film.

$\begin{array}{llll}6 & 1.5 & 1.7 & 2.27 \pm 0.04\end{array}$ A uniform blurring of gel spot with complete fixation on the film.

Note: $d 1$ is the initial diameter, $d 2$ is the final diameter, $S$ is the gel spot area after 1 hour of experiment

To determine the final concentration of sodium alginate, the determination of the adhesive ability of the gel with different concentrations of mucoadhesives $-0.25 \%, 0.5 \%$ and $1 \%$ was performed $[18,19]$. As a comparison drug, Gynodec was used. The results of the study are shown in Fig. 3. 


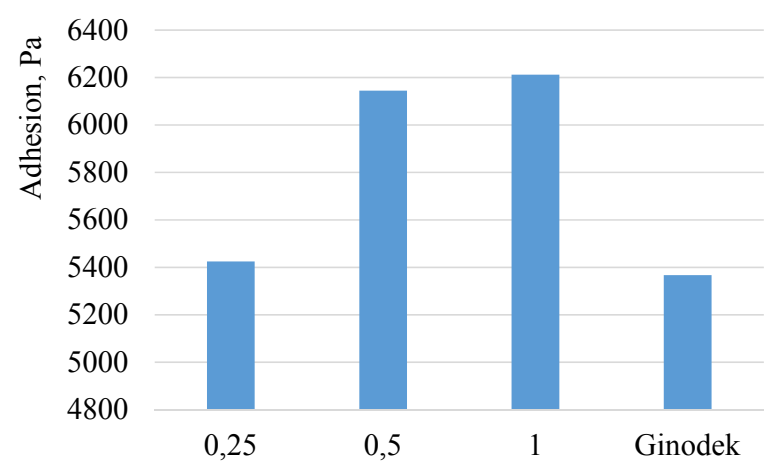

Fig. 3. The degree of samples' adhesion

\section{Discussion of the research results}

According to the results of the study (Fig. 1), it can be concluded that sample No. 2 with sodium alginate has the highest rate of distribution, which is almost identical to the comparator (1.56 and $1.53 \mathrm{~cm} / \mathrm{min}$, respectively).The samples number 3 and number 4 have the lowest values, their rate of distribution is $0.49 \mathrm{~cm} / \mathrm{min}$. Samples No. 2 and No. 6 flowed evenly over the film surface, while samples No. 1, 3, 4, and 5 stopped moving in a few minutes and formed a gel cluster in the form of a drop, indicating that the mucous membrane was covered unevenly [20].

The obtained results indicate that samples No. 2 and No. 6 have the highest internal cohesion indices, as evidenced by the area of spots and distribution coefficients, which make up 1.42 and 1.47 , respectively. In other samples, there is a decrease in the adhesion to the surface, which leads to deterioration of their fixation on the surface. The distribution coefficients increase to 1.68.

The next step was to determine the indices of samples fixation of on the surface of the application by the "flow" method. As shown in Table 2, all samples are capable of blurring over time. The closest value of the spot area to the reference preparation has sample No. 2 with sodium alginate as an adhesive. Visual observation makes it possible to conclude that only in the samples number 2 and 6 there is complete fixation of gel spots without changing their shape. The most unstable is sample No. 5 with OraRez, which has the largest spot area $(S=3.80)$, but during the experiment there is a blurring of the spot without fixing on the film. In other samples there is a change in shape, uneven blurring without or only with partial fixation on the surface of the film. The reduction of the area of the spots of other samples takes place in the row number $3=$ number $4>$ number 1 , which correlates with the data of previous studies.

The results of the study indicate that the adhesive ability of the sample with the of sodium alginate concentration $0.25 \%$ is almost identical to the preparation of comparison (Fig. 3). Increasing its concentration to $0.5 \%$ contributes to a significant increase in the force required to separate the two surfaces from 5380 to $6158 \mathrm{~Pa}$. A further increase in concentration to $1 \%$ does not lead to a significant increase in adhesion degree.

Thus, based on the performed studies, it was found that a rational concentration of sodium alginate in the composition of the gel to ensure its bioadhesive properties should be considered $0.5 \%$.

\section{Conclusions}

1. On the basis of the complex of physico-chemical studies, bioadhesion indicators of vaginal gel with resveratrol, depending on the type and concentration of mucoadhesives have been determined.

2. According to the distribution parameters on the surface of the genital mucosa model, it has been found that the best properties compared with other types of mucoadhesives has a sample containing sodium alginate.

3. The study by means of a strain gauge has found that the addition of sodium alginate at a concentration of $0.5 \%$ would provide a satisfactory adhesive ability of the vaginal gel.

4 The results of the study can be used in the further development of the composition and technology of vaginal drugs. 


\section{References}

[1] Ayupova, G. V., Fedotova, A. A., Bondarenko, K. R. et. al. (2012). Medicines of vaginal application for prevention and treatment of disorders of female urogenital ecosystem. News of Samara Scientific Centre of the Russian Academy of Sciences, 14 (5-2), 315-319.

[2] Jelvehgari, M., Rashidi, M., Mirza Mohammadi, S. (2007). Adhesive and spreading properties of pharmaceutical gel composed of cellulose polymer. Jundishapur Journal of Natural Pharmaceutical Products, 2, 45-58.

[3] Russo, E., Selmin, F., Baldassari, S., Gennari, C. G. M., Caviglioli, G., Cilurzo, F. et. al. (2016). A focus on mucoadhesive polymers and their application in buccal dosage forms. Journal of Drug Delivery Science and Technology, 32, 113-125. doi: http://doi.org/10.1016/j.jddst.2015.06.016

[4] Kharenko, E. A., Larionova, N. I., Demina, N. B. (2009). Mucoadhesive dosage forms (review). Chemistry and Pharmacy Journal, 43 (7), 17-24.

[5] Saraswathi, B., Balaji, A., Umashankar, M. S. (2013). Polymers in mucoadhesive drug delivery system-latest updates. International Journal of Pharmacy and Pharmaceutical Sciences, 5, 423-430.

[6] Acarturk, F. (2009). Mucoadhesive Vaginal Drug Delivery Systems. Recent Patents on Drug Delivery \& Formulation, 3 (3), 193-205. doi: http://doi.org/10.2174/187221109789105658

[7] Andrade, A. O., Parente, M. E., Ares, G. (2014). Screening of mucoadhesive vaginal gel formulations. Brazilian Journal of Pharmaceutical Sciences, 50 (4), 931-941. doi: http://doi.org/10.1590/s198482502014000400029

[8] Donnelly, R., Shaikh, R., Raj Singh, T., Garland, M., Woolfson, A. (2011). Mucoadhesive drug delivery systems. Journal of Pharmacy and Bioallied Sciences, 3 (1), 89-100. doi: http://doi.org/10.4103/09757406.76478

[9] Chatterjee, B., Amalina, N., Sengupta, P., Uttam Kumar Mandal, U. (2017). Mucoadhesive Polymers and Their Mode of Action: A Recent Update. Journal of Applied Pharmaceutical Science, 7, 195-203. doi: http://doi.org/10.7324/japs.2017.70533

[10] Anurova, M. N., Kashperko, A. S., Bakhrushina, E. O. (2018). Problems of vaginal mucosa modelling for determination of bioadgesion of vaginal gels by in vitro flow method. The Journal of Scientific Articles "Health and Education Millennium", 99-102.

[11] Tamagawa, H., Takahashi, Y. (2008). Adhesion force behavior between two gels attached with an electrolytic polymer liquid. Materials Chemistry and Physics, 107 (1), 164-170. doi: http://doi.org/10.1016/ j.matchemphys.2007.06.063

[12] Lee, J. W., Park Robinson, J. H. (2000). Bioadhesive-based dosage forms: the next generation. Journal of Pharmaceutical Sciences, 89, 850-866. doi: http://doi.org/10.1002/1520-6017(200007)89:7<850*:aidjps2>3.0.co;2-g

[13] Querobino, S. M., de Faria, N. C., Vigato, A. A., da Silva, B. G. M., Machado, I. P., Costa, M. S. et. al. (2019). Sodium alginate in oil-poloxamer organogels for intravaginal drug delivery: Influence on structural parameters, drug release mechanisms, cytotoxicity and in vitro antifungal activity. Materials Science and Engineering: C, 99, 1350-1361. doi: http://doi.org/10.1016/j.msec.2019.02.036

[14] Rose, S., Prevoteau, A., Elzière, P., Hourdet, D., Marcellan, A., Leibler, L. (2013). Nanoparticle solutions as adhesives for gels and biological tissues. Nature, 505 (7483), 382-385. doi: http://doi.org/10.1038/ nature12806

[15] Dizavandi, F. R., Ghazanfarpour, M., Roozbeh, N., Kargarfard, L., Khadivzadeh, T., Dashti, S. (2019). An overview of the phytoestrogen effect on vaginal health and dyspareunia in peri- and post-menopausal women. Post Reproductive Health, 25 (1), 11-20. doi: http://doi.org/10.1177/2053369118823365

[16] Ivaniuk, O. I., Yarnykh, T. G., Kovalevska, I. V. et. al. (2018). Rheology-based substantiation of a gel-former choice for vaginal gel. Journal of Pharmaceutical Sciences and Research, 10, 2825-2828.

[17] Albertini, B., Passerini, N., Di Sabatino, M., Vitali, B., Brigidi, P., Rodriguez, L. (2009). Polymer-lipid based mucoadhesive microspheres prepared by spray-congealing for the vaginal delivery of econazole nitrate. European Journal of Pharmaceutical Sciences, 36 (4-5), 591-601. doi: http://doi.org/ 10.1016/j.ejps.2008.12.009

[18] Amit, R., Choudhury, A., Sanjib, B., Suman, S. (2016). Phytoconstituent based mucoadhesive antifungal vaginal formulation: An effective and innovative approach. Bioscience Biotechnology Research Communications, 9, 694-701. 
[19] Masoudi, M., Rafieian Kopaei, M., Miraj, S. (2017). A comparison of the efficacy of metronidazole vaginal gel and Myrtus (Myrtus communis) extract combination and metronidazole vaginal gel alone in the treatment of recurrent bacterial vaginosis. Avicenna Journal of Phytomedicine, 129-136.

[20] Asadi, M., Forouhari, S., Jahromi, B. N. et. al. (2016). Comparison of the effects of Mycocin vaginal cream and Metronidazole vaginal gel on treatment of bacterial vaginosis: A randomized clinical trial. International Journal of Medical Research \& Health Sciences, 8, 250-256.

\title{
SCIENTIFIC AND PRACTICAL APPROACHES TO FORM THE LIST OF SOCIAL-PSYCHOLOGICAL CHARACTERISTICS FOR PHARMACY SPECIALIST
}

\author{
Rita Sahaidak-Nikitiuk \\ Department of Processes and Apparatuses of Chemical and Pharmaceutical Industries \\ National University of Pharmacy \\ 53 Pushkinska str., Kharkiv, Ukraine, 61002 \\ Mariana Harkusha \\ Department of Processes and Apparatuses of Chemical and Pharmaceutical Industries \\ National University of Pharmacy \\ 53 Pushkinska str., Kharkiv, Ukraine, 61002 \\ Svitlana Barnatovych \\ Department of Technology of Medicines, Organizations and Economics of Pharmacy \\ Lugansk State Medical University \\ 32 Budivelnikiv str., Rubizhne, Ukraine, 93012 \\ Svitlana Velma \\ Department of Pharmacoinformatics \\ National University of Pharmacy \\ 53 Pushkinska str., Kharkiv, Ukraine, 61002 \\ 0679267726.lana@gmail.com
}

\footnotetext{
Abstract

Nowadays according to employers, pharmacy specialist should be not only competent professional, but versed in the consumer psychology and result oriented, at the same time, i.e. concentrated on the pharmacy competitiveness increase and on maximal income and customer satisfaction.

The aim of the presented work was to investigate the social-psychological characteristics for pharmacy specialist essential in his or her professional activity, and to substantiate the list of these characteristics.

Materials and methods. Analytical, graphical and comparative methods, methods of descriptive and abstract modeling, system analysis and synthesis, taxonomy and cluster analysis were applied in the study.

Results. Social-psychological characteristics for pharmacy specialist methodologically should be selected and substantiated by the main stakeholders: employers, pharmacists, doctors, customers and graduation course students. The research algorithm to define the professionally important social-psychological characteristics for pharmacy specialist was suggested. The professionally important social-psychological characteristics regarding the requirements of employers from different countries to pharmacy specialists include sociability, responsibility, attentiveness, orderliness, and command-orientation. The main social-psychological characteristics for pharmacy specialists based on content analysis are attentiveness, sociability, indulgence, goodwill, responsibility, neatness, sensitivity, patience. Comparison of four research results for pharmacists, doctors, customers and graduation course students form specialty "Pharmacy" allowed to select and to substantiate the social-psychological characteristics for pharmacy specialist essential in his or her professional activity. They are goodwill, stress-stability, honesty, command-orientation, neatness, affability, decency, purposefulness, desire for learn and develop, grammatically correct language, non-conflictedness.
} 